\title{
Auditors Perceptions Towards the Effectiveness of the International Standard on Auditing 240 Red Flags: Evidence From Lebanon
}

\author{
Submitted $23 / 12 / 18,1^{\text {st }}$ revision $6 / 1 / 19,2^{\text {nd }}$ revision $15 / 2 / 19$, accepted $6 / 3 / 19$
}

Wajdi Hijazi ${ }^{1}$ and Rasha Mahboub ${ }^{2}$

\begin{abstract}
:
Most of the studies on auditors' perceptions towards the effectiveness of the international standard on auditing 240 Red Flags (RF) were conducted in developed economies.

This research, therefore, fills the gap by aiming to determine whether RF can be helpful for Lebanon certified public accountant (LCPA) working in auditing firms by detecting fraudulent financial reporting (FFR).

Data were collected using a questionnaire that was distributed to a random sample of 130 LCPA. The results support that there is a positive significant association between pressures and FFR occurrence in Lebanon.

However, there were no support for opportunities and attitudes to be associated with FFR occurrence. Moreover, the findings provide a strong evidence that ISA 240 RF for FFR can help external auditors in detecting material mis-statement (MM) due to fraud in Lebanon.

Therefore, the current research recommends LCPA working in the audit firms in Lebanon to focus their efforts more on high quality $R F$, which will in turn facilitate fraud detection in the financial statements.
\end{abstract}

Keywords: Fraud, LCPA, Fraudulent Financial Reporting, Red Flags, Lebanon.

\footnotetext{
${ }^{I}$ Faculty of Business Administration, Beirut Arab University, Lebanon Email: w.hijazi@bau.edu.lb

${ }^{2}$ Faculty of Business Administration, Beirut Arab University, Lebanon Email: r.mahboub@bau.edu.lb
} 


\section{Introduction}

A considerable increase in the reporting of financial frauds and subsequent business collapses led to worries about the accuracy of corporate financial reports. These worries have led to updating the auditing standards and laws to protect the investors and to push the regulators and auditors to prevent and detect such frauds (Lou and Wang, 2009). Business fraud had received remarkable and increasing attention from public, auditors, and regulators (Kassem and Higson, 2012). One of the most important theories that interpreted why violators perpetrate fraud is Cressey's theory. This theory was configured to "fraud triangle" (Kassem and Higson, 2012). This fraud triangle specifies pressure/incentive to commit fraud, opportunity to perform the fraud, or attitude/rationalization to vindicate fraud action. Such cases stands for "fraud-risk factors" (Lou and Wang, 2009).

FFR increases recently and this may lead to MM in the financial reports and harms the stockholders and creditors. Thus, the auditors should anticipate the probability of FFR occurrence (Kirkos et al., 2007). The AICPA acknowledges clearly the responsibilities of the auditors concerning fraud detection (Cullinan and Sutton, 2002).

Hence, auditors should work as detectives to investigate the validity of the evidences and the faithfulness of financial reports by depending on several techniques and procedures to detect the manipulations. One of these techeniques is depending on RF that can work as indicators of FFR. These RF are proxies for the existence of fraudulent activity; however, they do not assert the existence of fraud, they must be examined to affirm the presence of the fraudulent activity (Yücel, 2013).

Due to the importance of RF, the global accounting institutions depend on them in their rules and regulations because they provide signs about fraudulent actions. Lately, the international standard on auditing (ISA) No. 240 recommmends fro auditors to depend on $41 \mathrm{RF}$ in auditing the financial reports to detect fraud. (Hegazy and Kassem, 2010).

However, as reported by Rezaee et al. (2003) many studies indicated that those auditing standards and updated regulations have not improve the auditor's ability to discover fraud. Therefore, it is not clear to what extent the auditing regulations and standards had influenced the auditor's ability in preventing and documenting situations where fraud had been discovered (Hassink et al., 2010). Although the mentioned standards aimed to diminish the expectation gap by increasing the responsibility of the auditors in detecting fraud; however, the expectation gap remains (Hegazy and Kassem, 2010). Thus, it is significant to manage the risk of fraud through identifying the fraud risk elements depending on the fraud triangle.

There is little research linking the frauds in the financial statements with fraud Cressey's theory, although it is generally accepted by accounting academics, 
practitioners, and several regulatory agencies (Roden et al., 2016). Therefore, filling the expectation gap through investigating whether the ISA $240 \mathrm{RF}$ related to fraudulent financial statements will help external auditors in discovering fraud MM is needed.

Therefore, this research aims to identify a set of fraud risk factors, which then well known as the "fraud triangle" as well as investigate the roles of ISA 240 RF in aiding external auditors in detecting MM, and that through external auditor's assessment of $41 \mathrm{RF}$ while auditing the financial reports to discover the fraud in the financial statements.

Thus, in order to achieve the objectives of this research, two questions are developed. (1) What are the fraud risk elements proxies for pressure/incentive; opportunity and attitude/rationalization? In addition, (2) do ISA 240 RF related to FFR aid external auditors in discovering MM due to fraud? The outcomes of this research are significant for users of financial reports, academics, and standard setters. If the theory of Cressey is beneficial, then the usage of fraud risk factors included in ISA (240) may improve the confidence in the audited financial reports. In addition, the information gained from this research could benefit audit profession and audit standard setters by reflecting the importance of RF list to the external auditors. Finally, this research would support academies and researchers who have an interest in this field of research through suggesting further future research opportunities.

\section{Literature Review and Hypotheses Development}

When the external pressure ascended, the International Auditing and Assurance Standards Board (IAASB) issued in December 2009 the ISA (240) "The Auditor's Responsibilities Relating to Fraud in an Audit of Financial Statements" (Chong, 2013). This standard focuses on the external auditor's concerns of the risk that may lead to frauds and errors and illustrates the arguments on the limitations that impede the abilities of the auditors in detecting errors and frauds, especially management fraud. In addition, it focuses on distinguishing between fraud committed by management or employees; it also concentrates on the various discussions related to fraudulent financial reporting (Kirkos et al., 2007).

ISA (240) documented three cases that generally lead to MM associated with fraud risk:

(1) incentives/pressures;

(2) opportunities;

(3) attitudes/rationalizations.

These cases are named as "fraud-risk factors." In spite, these factors do not absolutely lead to the presence of fraud, they often presented in situations where fraud occurs (Lou and Wang, 2009). Next, the researchers will provide a brief 
descreption for the three components of fraud trangle as well auditing standards and auditors' responsibilities for detecting material fraud.

\subsection{Pressures/Incentives}

Pressure may emerge because of external statuses as industry, economy, or firm is operating situations that loom up the financial stability of the customer. In addition, managers may be under big pressure to accomplish and meet the anticipated sales or profitability goals, or to meet the anticipations of outside parties, such as stockholders, creditors, and analysts (Lou and Wang, 2009). Prior studies have divided pressures into four categories financial pressures, immoral (vice) pressures, job- linked pressures and other pressures. The studies reported that 95 percent of all frauds are related to financial and immoral pressures.

According to ISA 240, there are four main kinds of pressure, which may cause fraud in the financial reports. They are exterior pressure, financial stability, the personal financial conditions of the managers, and reaching the financial goals (ISA 240, 2015). Previous studies have indicated that there is a positive association between pressures and FFR. For instance, Lou and Wang (2009) revealed that managers might be under pressure that lead to the commitment of fraud in the financial reports if the financial stability and/or profitability are menaced by industry, economy, or firm operating situation. Suyanto (2009) demonstrated that managers usually manipulate financial reports to meet the requirements of the contract terms.

Therefore, it is expected to have a positive and significant association between financial tribulation and the presence of FFR. Skousen et al. (2009) reported that there is big pressure on management to reach the financial goals settled by the parties responsible for governance, involving profitability goals. Putra (2014) argued that if the managers possess large financial stake in a company, their personal financial status might be menaced by the company's financial achievements. As the managers' ownership in the firm increases, their personal financial wealth will rely on the performance of the firm. Then the managers will be more involved in committing accounting fraud to raise the value of the firm's stock to improve their personal wealth. Hence, based on the arguments of the previous studies, the first hypothesis is developed as follow:

$H_{1}$ : There is a positive significant association between pressures and FFR occurrence in Lebanon.

\subsection{Opportunities}

Fraud opportunities rise because of the presence of inherent risk in the industry. Besides, the type and degree of firm's operations complexity give opportunities to get involved in FFR. The case will be even worse in the presence of weak internal control system-especially inefficacious controls over the accounting and information 
systems- a commanding management pattern, and a shortage of segregation of duties among the staff (Chong, 2013). Albrecht et al. (2006) argued that opportunity is identified as averting punishments. Previous researchers documented six main elements that increase the opportunities for a person to perpetrate frauds in a firm. Deficiency of controls established for preventing or detecting fraudulent acts, deficiency in judging and measuring the performance, failure to punish fraud committers, inability to access to data and information, incapacity, unawareness and carelessness and shortage in fraud audit.

On the other hand, ISA 240 categorizes the opportunities that may cause FFR into four classes. These encompasses the type of industry, inefficacious oversighting and ineffective monitoring, firm structure, and deficiency in internal controls. Previous studies have indicated that there is a positive association between opportunities and FFR. For instance, Chen and Elder (2007) argued that there will more risk if there is inefficacious monitoring and oversighting of management due to dominance of management by a one person or a group in the absent of recompensating controls.

Companies with inefficacious monitoring would facilitate the CEO violation, and violation would lead to probable conflict of interest conditions that would decrease the stockholders' wealth. Moreover, Chen and Elder (2007) anticipated that companies with higher ratio of cash flow rights compared to control rights would be more probable to be involved in frauds related to financial statements, because concentrated ownership expedite the opportunism behavior of managers in issues related to financial statements. Skousen et al. (2009) mentioned that the type of company's industry could provide the opportunity to commit fraud in the financial statements. However, the impact of this factor on the occurrence of fraud is subjective and not easy to be verified. Lou and Wang (2009) asserted that efficacious internal control system can retain the quality of the company's financial reports and prohibit fraud occurrence. Putra (2014) demonstrated that the effect of this factor on the financial statements can be revealed in the accounts that depend much on the estimation and have subjective nature, such us inventory valuation. Consequently, based on the arguments of the previous studies, the second hypothesis is formulated as follow:

$H_{2}$ : There is a positive significant association between level of opportunities and FFR occurrence in Lebanon.

\subsection{Attitudes/Rationalizations}

Those engaged in fraud issues related to the financial statements usually rationalize their deceitful actions to be harmonized with their own code of ethics. Certain persons have attitudes, personalities, or ethical behavior that permit them to intentionally perpetrate fraudulent acts (Suyanto, 2009). Mostly any fraud includes the factors of rationalization. Most often, the committers of this type of fraud rationalize the roguery of their actions. The fraud committers usually have joint 
rationalizations to justify their acts. There are several reasons for attitudes that lead to fraud. For instance, inefficacious communication; failure of fulfillment, enhancement, or execution of the firm's ethical standards; management's aggressive involvement in choosing the accounting methods or sharing in the determination of important estimations (Chong, 2013).

In fact, the auditor's independence is considered a vital factor to achieve qualified financial reports. Regarding the role of external auditor on decreasing fraud, Chen and Elder (2007) mentioned that companies that frequently switch the external auditor are more probable to commit frauds in the financial reports. Moreove, Suyanto (2009) considers the sufficiency of financial reports disclosure a signal of the firm's cabpability to keep on as a going concern. Hence, based on the arguments of the previous studies, the research postulate the following hypothesis:

$H_{3}:$ There is a positive significant association between rationalizations and FFR occurrence in Lebanon.

\subsection{Auditing Standards and Auditors' Responsibilities for Detecting Material Fraud}

The primary step for discovering fraud is to know where to begin performing control. Moreover, identifying the elements that lead to fraud and consequently realizing the significant areas to accomplish elaborated assessment through anticipating the most risky accounts is an effective method to discover fraud. In this level, doubts and skepticism of the external auditor are actually significant. In addition, the external auditor should assess all procedures with skepticism whilst detecting frauds. The auditor should always believe that all records and financial reports may contain deceitful applications and any document can be forged. It is not a case of mistrust but an exigency for examination. External auditors should keep track of several indicators (RF) and apply different ways in discovering manipulations (Yücel, 2013).

Price Waterhouse explained RF as potential symptoms existing within the firm's business environment that would indicate a higher risk of an intentional misstatement of the financial statements (Yücel, 2013). For instance, Yücel (2013) suggested the usage of RF in detecting fraud detection; he argued that identifying the significant alert signals must aid the external auditors in performing better assessment of fraud risk. He also stated that whilst the present and suggested auditing standards ask external auditors to perform this assessment and evaluation, they do not supply the auditors with guidance that displays the relative significance of certain signals. Moyes et al. (2013) stated that external auditors should determine the actions that are considered as fraud risk factors or RF, which can point out to the pressures or incentives to perpetrate fraud, attitudes or rationalizations to vindicate perpetrating fraud, and opportunities to commit fraud. They argued that the risks of not discovering the significant misstatements due to fraud are considered more than 
the risks of not discovering significant misstatements due to errors. Kassem and Higson (2012) asserted that the ISA (240) encourages the external auditors to take in consideration both the exterior and interior elements that influence the firm and may generate pressure for managers or employees to do fraud, form the opportunity for fraud to be committed, and create an environment that enables managers or employees to rationalize perpetrating fraud. Thus, based on these discussions, the following hypothesis is postulated:

H4: ISA 240 RF for FFR can aid external auditors in detecting MM due to fraud in Lebanon.

\section{Research Methodology}

\subsection{Research Population and Research Sample}

The field study population is the LCPA working in the audit firms in Lebanon, which constitute of about 1300 LCPA. The sample of the field study is $10 \%$ of the population 130 questionnaires were distributed among LCPA working in these firms.

\subsection{Data Collection and Measurement of Variables}

The researchers used a questionnaire as a method for collecting data. The five-point Linkert scale is used in the design of the questionnaire, which is the research instrument. The questionnaire was developed after reviewing the recent literature regarding ISA (240) RF. The measurement variables used in this research Incentives/Pressures, Opportunities, Attitudes/Rationalizations (independent variables) and FFR occurrence in Lebanon (dependent variable) - were five point Likert-scale with 1 (strongly disagree), 2 (disagree), 3 (neutral), 4 (agree) and 5 (strongly agree). The questionnaire consists of four parts. Part I contain questions on the demographic characteristic of the respondents. Part II consists of 41 questions in three sections. Section A consists of 12 questions on the Incentives/Pressures to commit fraud; section B consists of 15 questions on the Opportunities to commit fraud; section $\mathrm{C}$ consists of 14 questions on Attitudes/Rationalizations when committing fraud. Part III consists of one question about FFR occurrence in Lebanon. The last part consists of three questions on whether ISA 240 RF for FFR can help external auditors in detecting MM due to fraud.

\section{Results and Discussions}

\subsection{Reliability and Construct Validity}

Prior to research variable measurement, the draft of measurement instrument was evaluated for content validity. To provide content validity, the questionnaire was revived and pre-tested, requesting the advice and recommendation from the experts. 
Five professors from the accounting field from Lebanese universities were requested to participate for the validity content. Any comments were used to improve the wording and flow of the terms in the questionnaire.

The Cronbach's alpha values for the three independent variables range from 0.539 to 0.771 exceeding the minimum alpha of 0.5 . Thus, the constructs measures are considered reliable. The results of reliability testing are presented accordingly in the Table (1) below.

Table 1. Results of Reliability Analysis of Red Flags

\begin{tabular}{|l|l|l|}
\hline & \# of Red Flags & Cronbach $\boldsymbol{\alpha}$ \\
\hline Incentives & 12 & .710 \\
\hline Opportunities & 15 & .771 \\
\hline Attitudes & 14 & .539 \\
\hline
\end{tabular}

Source: SPSS (20)

The researchers were used the mean to rank all RF for FFR according to their relative importance based on LCPA. The most important RF in incentives were "Fast growth or abnormal profitability in the firms within the same industry" (4.3981), "High competition or market demarcation, along with decreasing margins" (4.3883) and "High sensitivity to fast changes (i.e. the changes in interest rates, product obsolescence, or technology) (4.2718). The most important RF in opportunities were "Difficulty in recognizing the organization or persons who have controlling interest in the firm" (4.3981), "Important operations took place across global boundaries in countries where different business environments exist" (4.3883) and "High complicated organizational structure with unusual legal activities or managerial lines of authority" (4.2913). The most important RF in attitudes were "Repeating attempts by management to vindicate inadequate accounting related to materiality issues" (4.3981), "The practice done by management to commit to creditors, analysts, and other parties to reach excessive or unrealistic expectations" (4.3883) and "Restrictions on the auditor, which limit his/her access to information, or impede his/her ability to communicate efficaciously with parties charged with governance" (4.3592).

\subsection{Descriptive Statistics}

This section presents the descriptive statistics of each variables included in this research (Table 2).

Table 2. Descriptive Statistics of Variables

\begin{tabular}{|l|l|l|c|c|c|}
\hline & Range & Minimum & Maximum & Mean & $\begin{array}{c}\text { Std. } \\
\text { Deviation }\end{array}$ \\
\hline Incentives & 1.33 & 3.50 & 4.83 & 4.11 & .35 \\
\hline Opportunities & 1.40 & 3.47 & 4.87 & 4.11 & .33 \\
\hline Attitudes & 1.14 & 3.36 & 4.50 & 3.89 & .26 \\
\hline
\end{tabular}




\begin{tabular}{|l|l|l|l|l|l|}
\hline Fraud & 3.00 & 2.00 & 5.00 & 3.85 & .83 \\
\hline
\end{tabular}

Source: SPSS (20)

Table 2 shows that the average of all variables range from 3.85 to 4.11 and the SD range from .26 to .83 . This means that all the respondents are agree that the 41 statements are related to ISA $240 \mathrm{RF}$.

\subsection{Correlation Analysis}

Table (3) shows a significant positive correlation between fraud and pressures as well as between fraud and opportunities. More specifically Pearson's correlation coefficients between fraud and pressures as well between fraud and opportunities stand respectively at $39 \%$ and $31 \%$ and they are significant at $1 \%$. Moreover, this table shows strong significant correlations between independent variables with each other.

Table 3. Correlation Analysis

\begin{tabular}{|l|l|l|l|l|}
\hline & Pressures & Opportunities & Attitudes & Fraud \\
\hline Pressures & 1 & & & \\
\hline opportunities & $.894^{* *}$ & 1 & & \\
\hline Attitudes & $.832^{* *}$ & $.940^{* *}$ & 1 & \\
\hline Fraud & $.390^{* *}$ & $.309^{* * *}$ & .192 & 1 \\
\hline
\end{tabular}

Source: SPSS (20)

\subsection{Regression Analysis}

In order to accomplish the main objective of this research, multiple regression analysis was conducted.

Table 4. Model Summary

\begin{tabular}{|c|c|c|c|c|}
\hline Model & R & R Square & $\begin{array}{c}\text { Adjusted } \\
\text { Square }\end{array}$ & $\begin{array}{c}\text { Std. Error of the } \\
\text { Estimate }\end{array}$ \\
\hline 1 & $.486^{\mathrm{a}}$ & .237 & .213 & .73896 \\
\hline
\end{tabular}

a. Predictors: (Constant), Pressures, Opportunities, Attitudes

Source: SPSS (20)

The findings of the model indicate $\mathrm{R}$ of $0.486, \mathrm{R}$ square of 0.237 and adjusted $\mathrm{R}$ square of 0.213 . This implies that $23.7 \%$ of the variations in fraud is explained by the independent variables of the research.

Table 5. ANOVA

\begin{tabular}{|l|l|c|l|l|l|l|}
\hline \multicolumn{2}{|c|}{ Model } & Sum of Squares & df & Mean Square & F & Sig. \\
\hline \multirow{4}{*}{1} & Regression & 16.756 & 3 & 5.585 & 10.229 & $.000^{\mathrm{a}}$ \\
\cline { 2 - 7 } & Residual & 54.059 & 99 & .546 & & \\
\cline { 2 - 7 } & Total & 70.816 & 102 & & & \\
\hline
\end{tabular}


Predictors: (Constant), Att, Press, opp

Dependent Variable: Fraud

Source: SPSS (20)

The ANOVA findings from Table (5) indicate F calculated of 10.229 and p-value of .000 ; this is an indicator that the overall regression model was significant.

Table 6. Coefficient

\begin{tabular}{|c|l|l|l|l|c|c|}
\hline \multicolumn{2}{|c|}{ Model } & \multicolumn{2}{l|}{$\begin{array}{l}\text { Unstandardized } \\
\text { Coefficients }\end{array}$} & \multicolumn{1}{l|}{$\begin{array}{l}\text { Standardized } \\
\text { Coefficients }\end{array}$} & & \\
\cline { 3 - 7 } \multicolumn{2}{c|}{} & B & Std. Error & Beta & t & Sig. \\
\hline \multirow{2}{*}{1} & (Constant) & 2.758 & 1.206 & & 2.287 & .024 \\
\cline { 2 - 7 } & Pressures & 1.280 & .473 & .532 & 2.708 & .008 \\
\cline { 2 - 7 } & Opportunities & 1.496 & .798 & .601 & 1.875 & .064 \\
\cline { 2 - 7 } & Attitudes & -2.655 & .842 & -.816 & -3.153 & .002 \\
\hline
\end{tabular}

Source: SPSS (20)

Table (6) shows that the coefficient of pressures has the positive expected sign (1.280) and it is significant (.008). This indicates that pressures is significantly positively influencing the FFR occurrence in Lebanon. Hence, hypothesis 1 is accepted. The coefficient of opportunities is positive (1.496) and insignificant (.064). This reveals that there exists a positive influence of opportunities on the FFR occurrence in Lebanon, but it is not statistically significant. Consequently, hypothesis 2 is rejected. The coefficient of attitudes has the negative unexpected sign (-2.655) and it is significant (.002). This signifies that attitude is significantly negatively influencing the FFR occurrence in Lebanon. Hence, hypothesis 3 is rejected.

\subsection{One-Sample Wilcoxon Signed Rank Test}

According to Table (7), p- value is 0.000 (significant). Thus, the null hypothesis has been rejected. Consequently, there is a sufficient evidence at 0.05 level to conclude that the median of IAS 240 differs significantly from 3 . Hence, hypothesis 4 is accepted.

Table 7. One-Sample Wilcoxon Signed Rank Test

\begin{tabular}{|c|c|c|c|}
\hline $\begin{array}{c}\text { Null } \\
\text { Hypothesis }\end{array}$ & Test & Sig. & Decision \\
\hline $\begin{array}{c}\text { Median of IAS } \\
240=3\end{array}$ & $\begin{array}{l}\text { One-Sample } \\
\text { Wilcoxon Signed } \\
\text { Rank Test }\end{array}$ & 0.000 & $\begin{array}{l}\text { Reject the null } \\
\text { hypothesis }\end{array}$ \\
\hline
\end{tabular}

Asymptotic Significances are displayed. The significant level is 0.05

Source: SPSS (20)

\section{Research Limitation and Recommendation}


This research aims to identify a set of fraud risk factors that had been adopted by ISA (240) as well to investigate the roles of ISA $240 \mathrm{RF}$ in aiding external auditors in Lebanon in detecting MM in the financial statements. To achieve the intended objective, the research was based on a self- administered questionnaire of 41-RF. By employing multivariate OLS model, the finding of the research shows that there is a positive significant association between pressures and FFR occurrence in Lebanon. However, there were no support for opportunities and attitudes to be associated with FFR occurrence in Lebanon. Moreover, the finding provides a strong evidence that ISA $240 \mathrm{RF}$ for FFR can aid external auditors in detecting MM due to fraud in Lebanon. Hence, the list of specific RF for FFR that were used in this research can be used in conjunction with SAS 99 RF to enhance external auditors' ability in detecting FFR. Therefore, it is believed that these findings contribute to the academicians to further spread out the research in this area, users of financial reports, audit profession and audit standard setters by reflecting the importance of RF list to the external auditors.

The research is not without limitations. The researchers were not able to get more than 130 LCPA working in the audit firms in Lebanon out of 1300 LCPA to fill in the questionnaire and thus the results cannot be generalized to all LCPA working in Lebanon. Future research is needed to increase the sample size to generalize the results. This may provide additional insights into the external validity of the findings. The current research examined the RF for FFR based on a questionnaire; future research should test them using other methods like experiments or interviews. The researchers tried to list every possible RF for FFR but certainly, there can be other RF in the literature that are not mentioned in this research. Thus, future research should be more directed toward listing other RF for FFR. Therefore, the current research recommends LCPA working in the audit firms in Lebanon to focus their efforts more on high quality RF, which will in turn facilitate fraud detection in the financial statements.

\section{References:}

Albrecht, W.S., Albrecht, C.O., Albrecht, C.C. and Zimmerman, M.F. 2006. Fraud Examination (fourth Ed.). Thomson Southwestern.

Chen, K.Y. and Elder, R.J. 2007. Fraud risk factors and the likelihood of fraudulent financial reporting: evidence from Statement on Auditing Standards No. 43 in Taiwan. Working paper.

Chong, G. 2013. Detecting fraud: what are auditors' responsibilities? Journal of Corporate Accounting and Finance, 24(2), 47-53.

Cullinan, C.P. and Sutton, S.G. 2002. Defrauding the public interest: a critical examination of reengineered audit processes and the likelihood of detecting fraud. Accounting Journal Articles. Paper 105. Available at: https://digitalcommons.bryant.edu/acc_jou/105

Hassink, H., Meuwissen, R. and Bollen, L. 2010. Fraud detection, redress and reporting by auditors. Managerial Auditing Journal, 25(9), 861-881.

Hegazy, M. and Kassem, R. 2010. Financial reporting fraud: do red flags really help? 
Journal of Economics and Engineering, 1(4), 69-79.

International Standard on Auditing (240) (ISA 240). 2015. The Auditor's Responsibilities Relating to Fraud in an Audit of Financial Statement. IFAC.

Kassem, R. and Higson, A.W. 2012. The new fraud triangle model. Journal of Emerging Trends in Economics and Management Sciences, 3(3), 191-195.

Kirkos, E., Spathis, C. and Manolopoulos, Y. 2007. Data mining techniques for the detection of fraudulent financial statements. Expert Systems with Applications, 32(4), 9951003.

Lou, Y.I. and Wang, M.L. 2009. Fraud risk factor of the fraud triangle assessing the likelihood of fraudulent financial reporting. Journal of Business and Economics Research, 7(2), 61-78.

Moyes, G.D., Young, R. and Din, H.F.M. 2013. Malaysian internal and external auditor perceptions of the effectiveness of red flags for detecting fraud. Int. J. Auditing Technology, 1(1), 91-106.

Putra, A.P. 2014. Fraud triangle, pressure, opportunity, and rationalization and the level of accounting irregularities in Indonesia. Available at: ibs.ac.id.

Rezaee, Z., Olibe, K., and Minmier, G. 2003. Improving corporate governance: the role of audit committee disclosures. Managerial Auditing Journal, 18(6/7), 530-537.

Roden, D.M., Cox, S.R., Kim, J.Y. 2016. The fraud triangle as a predictor of corporate fraud. Academy of Accounting and Financial Studies Journal, 20(1), 80-92.

Skousen, C.J., Smith, K.R. and Wright, C.J. 2009. Detecting and predicting financial statement fraud: the effectiveness of the fraud triangle and SAS No. 99. Advances in Financial Economics, 13, 53-81.

Suyanto, S. 2009. Fraudulent financial statement evidence from Statement on Auditing

Standard No. 99. Gadjah Mada International Journal of Business, 11(1), 117-144.

Yücel, E. 2013. Effectiveness of red flags in detecting fraudulent financial reporting: an application in Turkey. Journal of Accounting and Finance, 60, 39-158. 